\title{
Development of a New
} Multiplying Assembly for
Research, Validation,
Evaluation, and Learning

\section{IEEE 2012 Nuclear Science Symposium}

\author{
David L. Chichester \\ Mathew T. Kinlaw
}

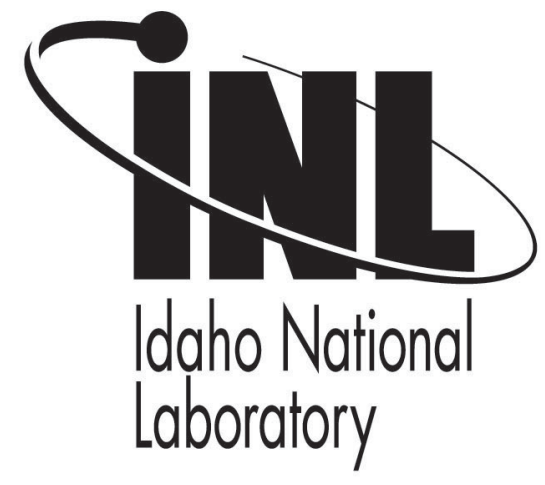

This is a preprint of a paper intended for publication in a journal or proceedings. Since changes may be made before publication, this preprint should not be cited or reproduced without permission of the author. This document was prepared as an account of work sponsored by an agency of the United States Government. Neither the United States Government nor any agency thereof, or any of their employees, makes any warranty, expressed or implied, or assumes any legal liability or responsibility for any third party's use, or the results of such use, of any information, apparatus, product or process disclosed in this report, or represents that its use by such third party would not infringe privately owned rights. The views expressed in this paper are not necessarily those of the United States Government or the sponsoring agency. 


\title{
Development of a New Multiplying Assembly for Research, Validation, Evaluation, and Learning
}

\author{
David L. Chichester, Senior Member, IEEE, and Mathew T. Kinlaw
}

\begin{abstract}
A new multiplying test assembly is under development at Idaho National Laboratory to support research, validation, evaluation, and learning. The item is comprised of three stacked, highly-enriched uranium (HEU) cylinders, each $11.4 \mathrm{~cm}$ in diameter and having a combined height of up to 11.7 $\mathrm{cm}$. The combined mass of all three cylinders is $20.3 \mathrm{~kg}$ of HEU. Calculations for the bare configuration of the assembly indicate a multiplication level of $>3.5\left(k_{\text {eff }}=0.72\right)$. Reflected configurations of the assembly, using either polyethylene or tungsten, are possible and have the capability of raising the assembly's multiplication level to greater than 10 . This paper will describe the MCNP calculations performed to assess the assembly's multiplication level under different conditions and describe the resources available at INL to support the use of these materials. We will also describe some preliminary calculations and test activities using the assembly to study neutron multiplicity.
\end{abstract}

\section{INTRODUCTION}

$\mathrm{N}$ eutron multiplication in assemblies of special nuclear material (SNM) is at the core of the discipline of nuclear engineering. It is important to be able to accurately predict the inherent ability of fissionable material assemblies to sustain nuclear chain reactions, and to predict how this characteristic of fissionable material assemblies will change due to different changes in physical parameters. Over the last half-century computer modeling and simulations have grown to become the primary research tool nuclear engineers use to understand these effect. Computer simulations are routinely used to explore how neutrons interact in many different types of multiplying assemblies, exploring problems ranging from reactors, to nuclear waste storage and disposition, to nonproliferation and nuclear security. However, hands-on experimental investigations and experimentation with SNM remains an invaluable component to work in this field.[1] Unfortunately, for several reasons, access to fissionable material for performing neutron multiplication experiments has diminished over the last two decades.

For several years researchers at Idaho National Laboratory (INL) have been working to develop and improve safe and secure access to SNM for research, validation, evaluation, and learning activities. The locus for these activities is INL's Materials and Fuels Complex (MFC) and the former ZeroPower Physics Reactor (ZPPR) facility. The ZPPR area

Manuscript received November 11, 2012. Idaho National Laboratory is operated for the U.S. Department of Energy by Battelle Energy Alliance under DOE contract DE-AC07-05-ID14517.

D. L. Chichester (telephone: 208-526-8920, e-mail: david.chichester@inl.gov) and M. T. Kinlaw (telephone: 208-526-6448, email: mathew.kinlaw@inl.gov) are both with Idaho National Laboratory, Idaho Falls, Id., 83415, USA.

The author's would like to acknowledge the support of Idaho National Laboratory's Laboratory-Directed Research and Development (LDRD) program for this work. includes several work areas including, most notably, the former reactor cell. The cell is a large high-bay area with a low-scatter floor and a high-capacity overhead crane. The facility possesses a diverse range of SNM for use in experiments including an inventory with multiple-grade plutonium items and multiple-enrichment uranium items, in both metallic and oxide forms.[2]
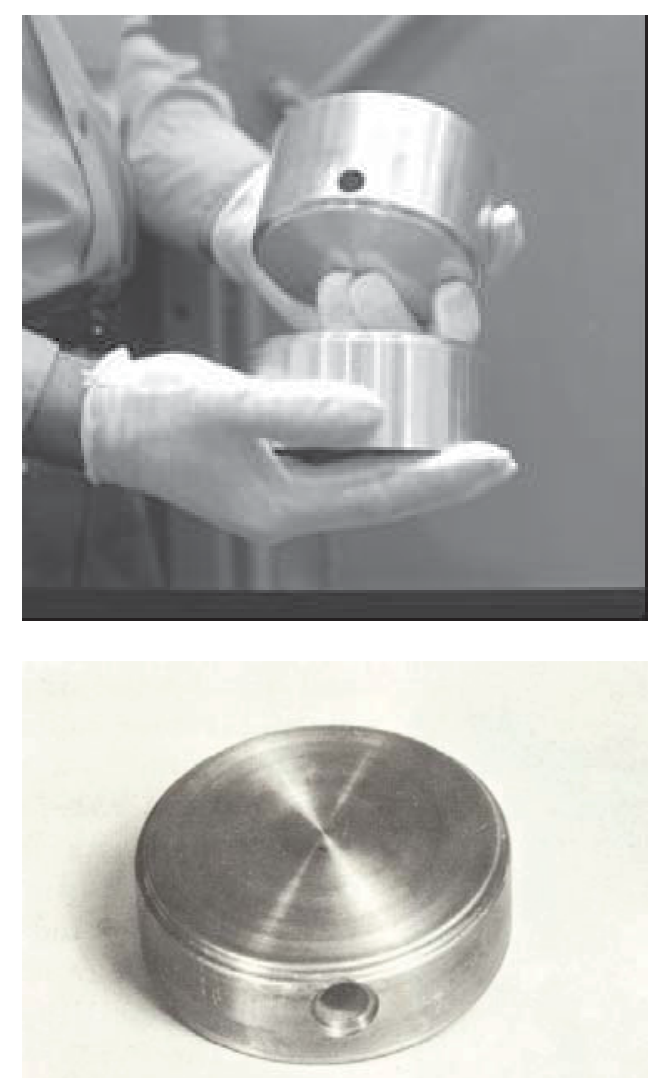

Fig. 1 An archival photograph of the three parts of the AFSR core (top) and a close-up photograph of the middle-section of the core (bottom).

Most recently, we have started to use a unique item in the ZPPR inventory - the Argonne Fast Source Reactor (AFSR) core. The AFSR core was previously used as the core of a low-power physics reactor at Argonne National Laboratory West. It consists of three distinct components, top, middle, and bottom, in the shape of cylindrical disks designed to be stacked one on top of another. The disks are each $11.4 \mathrm{~cm}$ in diameter. The top section is $3.3-\mathrm{cm}$ thick and weighs $5.9 \mathrm{~kg}$; its enrichment is $93.5 \%$. The middle section is $3.3-\mathrm{cm}$ thick and weighs $5.5 \mathrm{~kg}$; its enrichment is $93.4 \%$. It has a $1.2-\mathrm{cm}$ diameter hole entering from the outer edge going through the middle of the disk and exiting the other side. This hole can hold a radioisotope neutron source or other small item. The 
bottom section is $5.1-\mathrm{cm}$ thick and weighs $8.9 \mathrm{~kg}$; its enrichment is $93.5 \%$. A photograph of all three parts of the AFSR core, and a close-up photograph of the middle section of the core, is shown in Fig. 1.

After developing new work control documentation and performing safety reviews to support using the AFSR core, it is now once-again available at INL for hands on research. There are many potential uses for this assembly. One primary use is as an educational aid for teaching people about nuclear criticality and safe practices. Another important use is support research related to developing instrumentation aimed at analyzing neutron multiplication. Coupled with this purpose is using the AFSR core for validating analytical and numerical models used in reactor physics kinetics. Lastly, an important use of the AFSR core is for test and evaluating instrumentation designed to analyze neutron multination signatures from fissionable materials. Coupling the AFSR core with the support infrastructure to allow changing the neutron multiplication (via changing geometry, changing reflectors, changing moderators, etc) produces a versatile Multiplying Assembly for Research, Validation, Evaluation, and Learning - MARVEL. This paper presents a background discussion of the value and importance of performing handson experiments with multiplying assemblies, presents simulation studies carried out to assess the neutron multiplication levels possible with different MARVEL configurations, and presents a simple example of an experimental use of two-thirds of the MARVEL to generate a $1 / M$ plot.

\section{A. Research, Validation, and Evaluation}

In collaboration with partners at other institutions INL has been involved in research studying experimental methods related to measuring and interpreting neutron multiplicity and neutron multiplication for several years.[3-8] The development of the MARVEL test capability is based in part on interest in expanding the Laboratory's capabilities for performing work in this area. While prior work at INL has used large masses of SNM (e.g., $10 \mathrm{~kg}$ of HEU, $4 \mathrm{~kg}$ of $\mathrm{Pu}$ ), rarely has prior work involved fissionable assemblies having multiplication levels in excess of 2. (One notable exception to this is prior work using a special set of inspection objects containing various combinations of uranium and plutonium.[9])

Most experimental research campaigns dealing with neutron multiplicity and neutron multiplication measurements are partnered with simulation activities. Typically only a handful of experiments may be performed during a particular testing cycle. However, ample access to high performance computing resources can augment parameter-bounding experiments to perform parametric analysis of variables not accessible through experiments, and to exhaustively carry-out sensitivity analyses for varying different parameters singly and in combination.[10] In a complimentary fashion, for computationally focused research efforts key measurements performed during experimental efforts are critically important for validating the accuracy and legitimacy of using simulation codes and associated post-processing algorithms for analysis and interpretation.[11]
An important subset of activities that takes place at INL's ZPPR facility is testing to evaluate the performance and use of commercial instrumentation designed to detect and characterize radioactive materials. Development of the MARVEL test capability will augment work performed at INL in this area by providing an accessible, variable, and repeatable multiplying assembly to use for testing different neutron multiplicity and neutron multiplication measuring instruments and systems.

\section{B. Learning: Criticality Safety Training}

Understanding the complicated and interdependent phenomena that impact how neutrons interact in nuclear material provides the foundation for designing and operating nuclear reactors. At a more personal level, this understanding is also vitally important for individuals charged with working with SNM, those who design instrumentation and systems to handle and process fissionable material, and those who ensure that these activities are performed safely.[12,13]

At INL a key resource for fissile material handlers (FMHs) and criticality safety officers (CSOs) is the study guide "Criticality Safety Basics for INL FMHs and CSOs."[13] This documents provides FMH and CSO candidates a comprehensive overview of the principles and underlying concepts of criticality safety and stresses the importance of criticality safety when handling fissionable materials outside nuclear reactors. As a part of this training, INL uses the mnemonic expression MERMAIDS to assist those working with fissionable materials in remembering the eight key criticality control factors:

- Mass

- Enrichment

- Reflection

- Moderation

- Absorption (neutron capture)

- Interaction

- Density and concentration

- $\quad$ Shape (geometry)

While classroom instruction, mentored training, and reading about these phenomena can provide a strong basis for working safely with fissionable materials, hands-on experiences can provide deeper and more-lasting understandings in some cases. Emphasizing this, the U.S. Department of Energy (DOE) has made a requirement that criticality safety engineers (CSEs) have a hands on experimental training experience with criticality "... to facilitate familiarity with the factors contributing to criticality, the physical behavior of systems at and near criticality, and a theoretical understanding of neutron multiplication processes in critical and subcritical systems."[14] The new multiplying assembly at INL will be used to support hands-on training exercises with existing and future INL FMH and CSO candidates, and to augment the training and continuing education of INL criticality safety engineers (CSEs).

\section{Neutron Multiplicity}

Neutron multiplicity, $v_{n}$, prompt, refers to the number of neutrons emitted when an atom undergoes fission. [15] These neutrons are emitted 'promptly,' during the scission of the atom, and should not be confused by 'delayed' neutrons 
subsequently produced in the decay of $\beta$-unstable fission product atoms. The fission event may be spontaneous, owing to the natural decay of the radioactive atom, or it may be induced through a nuclear reaction, such as absorption of a neutron. The specific number of neutrons that will be emitted during a particular fission event is not predictable a priori but the distribution of the numbers of neutrons produced under identical circumstances, when repeated many times, is predictable and can be defined by a probability distribution for such events. These probability distributions are specific for each isotope, and specific depending upon the initiating conditions of the fission event (e.g., spontaneous fission versus neutron induced fission). For induced fission these distributions are further defined by the type and energy of the particle inducting the fission. Additional variables in the neutron multiplicity exit in terms of the energy and angular distributions of the prompt fission neutrons. A mean neutron multiplicity value, $\bar{v}_{\text {prompt }}$, may be defined for each probability distribution.

Neutron multiplicity is an important concept in the nuclear reactor physics and in nuclear safeguards. The MARVEL either system can provide a unique test-case for studying neutron multiplicity allowing, for example, studies comparing the neutron multiplicity from ${ }^{238} \mathrm{U}$ spontaneous fission and $235 \mathrm{U}$ neutron-induced fission (with a source driver) under different reflector/moderator conditions.

\section{Neutron Multiplication, $k_{\text {eff }}$, and $1 / M$}

Neutron multiplication, $M$, refers to the inherent characteristics of an assembly of fissionable material to extend the lifetime of a population of neutrons introduced into the assembly due to fission. Two terms may be defined, total multiplication and leakage multiplication.[16-19] The total multiplication, $M_{T}$, is the total number of neutrons produced in a fissionable assembly due to the introduction of one neutron into the assembly. The leakage (or net) multiplication, $M_{L}$, is the total number of neutrons that escape from a fissionable assembly due to the introduction of one neutron into the assembly. The leakage multiplication accounts for neutron production and capture in the assembly, and includes the source neutrons. It is not possible to measure the total number of neutrons produced in a fissionable assembly due to fission. Therefore, for experiments with multiplying assemblies, $M_{L}$ is the multiplication term of primary interest since it is the neutrons escaping the assembly which are measured.

The leakage multiplication may be defined as

$$
M_{L}=1+Q_{f}\left(\bar{v}_{\text {prompt }}-1-\alpha\right),
$$

where $Q_{f}$ is the number of fissions (on average) produced by introduction of one neutron into the system, $\bar{v}_{\text {prompt }}$ is the neutron multiplicity for the system, and $\alpha$ is the ratio of the neutron capture cross section to the fission cross section in the assembly, for the mean neutron energy in the system.[19]

Leakage multiplication is often related to the effective multiplication factor, $k_{\text {eff, }}$ of a fissionable assembly. The effective multiplication factor is the ratio, as shown in (2), of the neutrons produced by fission in one generation to the number of neutrons lost through absorption and leakage in the preceding generation.[20] $k_{\text {eff }}=\frac{\begin{array}{c}\text { neutron production from fission in one generation } \\ \text { neutron absorption in the } \\ \text { preceding generation }\end{array}+\begin{array}{c}\text { neutron leakage in the } \\ \text { preceding generation }\end{array}}{\text { prection }}$

For a system with $k_{\text {eff }}$ close to unity (near critical), the relationship between $M_{L}$ and $k_{\text {eff }}$ is

$$
M_{L}=\frac{1}{1-k_{e f f}} .
$$

For a system not close to critical, however, the measured neutron leakage from a fissionable assembly is related to $k_{\text {eff }}$ by the somewhat more complicated relation of (4).

$$
M_{L}=1+\frac{k_{\text {eff }}\left(\bar{v}_{\text {prompt }}-1-\alpha\right)}{\bar{v}_{\text {prompt }}\left(1-k_{\text {eff }}\right)} .
$$

When performing subcritical neutron multiplication experiments it is often common to work in an iterative approach. One begins with some starting condition for the experiment; for example, a bare assembly of fissionable material (when using HEU a separate neutron source is often used, to increase the neutron signal strength). A measure of the leakage neutron signal, $N_{0}$, is recorded with an appropriate detector. Then, modifications are made to the system that increase $k_{\text {eff }}$ for the system (e.g., adding fuel to the system, or adding moderating materials to partially surround the system), increasing the leakage multiplication of the system and increasing the measured neutron signal to a new level, $N_{l}\left(N_{l}\right.$ $>N_{0}$ ). This process is continued, allowing collection of increasingly larger neutron counts, $N_{i}$. Presuming that the system cannot be made critical, then eventually, as $i \rightarrow \infty, \mathrm{N}$ reaches some equilibrium value, $N_{\infty}$. Starting with $N_{0}$, for each change in the experiment, the ratio $M=N_{i} / N_{0}$ is recorded. A plot of $1 / M$ versus the changes being made to the system (e.g., fuel mass addition, moderator mass addition, etc.) is then made for each step change of the variable. Initially, $M$ is often observed to increase significantly as changes are made to the system. If the system is capable of going critical then $\mathrm{M} \rightarrow \infty$; however, if the system cannot go critical then $M$ (and $1 / M$ ) will trend to an equilibrium level where further adjustments to the system no longer increase the system's multiplication level. At this point the $k_{\text {eff }}$ value for the system is also constant.

\section{E. Neutron Fission Parameters}

The MARVEL core components are comprised of ${ }^{235} \mathrm{U}$ and ${ }^{238} \mathrm{U}$, with a ${ }^{235} \mathrm{U}$ enrichment of approximately $93.5 \%$. Important neutron-induced fission parameters for uranium are provided in Table 1. For the MARVEL material enrichment the total spontaneous neutron yield is approximately $1 \mathrm{~s}^{-1} \mathrm{~kg}^{-1}$. The neutron yields for each component (neglecting multiplication for the moment) are 5.9, 5.5, and $8.9 \mathrm{~s}^{-1}$ for the top, middle, and bottom sections, respectively. This level is quite low; to augment this an external neutron source is used for experiments. Both an americium-lithium $(\alpha, n)$ neutron source and a ${ }^{252} \mathrm{Cf}$-spontaneous fission source are available. The preferred configuration is to insert the ${ }^{252} \mathrm{Cf}$ source inside the hole in the middle section of the MARVEL assembly; this serves as the driving source for the assembly, providing the base-line neutron intensity for determining multiplication as a) 
additional components of the core are moved within proximity of the middle section and/or b) reflectors and/or moderators are brought within proximity of the assembly. It is also possible to drive the assembly using an external, pulsed neutron source using either a deuterium-deuterium (DD, 2.5$\mathrm{MeV}$ ) or deuterium-tritium (DT, 14.1-MeV) electronic neutron generator (ENG).

TABLE $1{ }^{235} \mathrm{U}$ AND ${ }^{238} \mathrm{U}$ NEUTRON FISSION PARAMETERS $[21,22,23]$

\begin{tabular}{|c|c|c|c|}
\hline \multicolumn{2}{|c|}{ Parameter } & \multirow{2}{*}{$\begin{array}{c}{ }^{235} \mathbf{U} \\
0.299\end{array}$} & \multirow{2}{*}{$\frac{{ }^{238} \mathbf{U}}{13.6}$} \\
\hline$Y_{S F}$ & $\begin{array}{c}\text { Spontaneous- } \\
\text { fission (SF) } \\
\text { neutron } \\
\text { yield, } \\
\mathrm{n} \mathrm{s}^{-1} \mathrm{~kg}^{-1} \\
\end{array}$ & & \\
\hline$\sigma$ & $\begin{array}{l}\text { Fission } \\
\text { cross } \\
\text { section, } \\
\text { barns }\end{array}$ & $\begin{array}{c}2.08(14.1 \mathrm{MeV}) \\
1.29(2 \mathrm{MeV}) \\
2734(\text { thermal })\end{array}$ & $\begin{array}{c}1.15(14.1 \mathrm{MeV}) \\
0.53(2 \mathrm{MeV})\end{array}$ \\
\hline $\bar{v}_{\text {prompt }}$ & $\begin{array}{c}\text { Average } \\
\text { prompt } \\
\text { neutron } \\
\text { yield } \\
\text { (multiplicity), } \\
\text { n fission }^{-1} \\
\end{array}$ & $\begin{array}{c}4.6(\sim 14 \mathrm{MeV}) \\
2.57 \text { (fission spec.) } \\
2.41 \text { (thermal) } \\
1.86(\mathrm{SF})\end{array}$ & $\begin{array}{c}4.5(\sim 14 \mathrm{MeV}) \\
2.79 \text { (fission spec.) } \\
2.01(\mathrm{SF})\end{array}$ \\
\hline $\bar{E}_{\text {prompt }}$ & $\begin{array}{l}\text { Average } \\
\text { prompt } \\
\text { neutron } \\
\text { energy, } \\
\mathrm{MeV}\end{array}$ & $\begin{array}{l}2.03(14 \mathrm{MeV}) \\
1.935 \text { (thermal) }\end{array}$ & $1.99(14 \mathrm{MeV})$ \\
\hline $\bar{v}_{\text {delayed }}$ & $\begin{array}{l}\text { Average } \\
\text { delayed } \\
\text { neutron } \\
\text { yield, } \\
\text { n fission } \\
\end{array}$ & $\begin{array}{c}0.0165(1.45 \mathrm{MeV}) \\
0.0158 \text { (thermal) }\end{array}$ & $0.0412(3.01 \mathrm{MeV})$ \\
\hline $\bar{E}_{\text {delayed }}$ & $\begin{array}{c}\text { Average } \\
\text { delayed } \\
\text { neutron } \\
\text { energy, } \\
\text { MeV }\end{array}$ & 0.43 & 0.49 \\
\hline
\end{tabular}

Values followed by parenthesis indicate quantities associated with fission induced by neutrons with an energy or energy-spectrum given in the parenthesis.

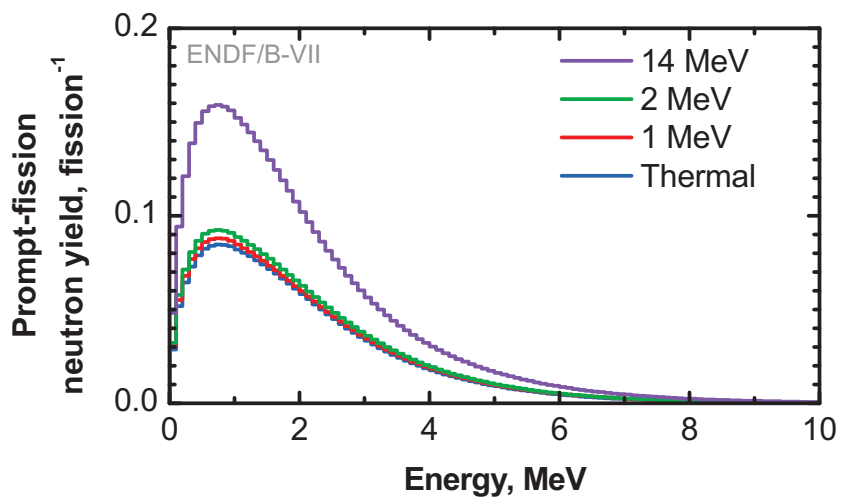

Fig. 2 Neutron spectrum from ${ }^{235} \mathrm{U}$ due to induced fission from source neutrons ranging from thermal energies to $14 \mathrm{MeV}$. (Data from the ENDF/BVII database.)
Whether the assembly is driven via spontaneous fission, either of the two radioisotope neutron sources, DD- or DTENGs, or reflected and/or moderated neutrons originating from these sources, the neutron fission spectrum mean energy is expected to be similar, as shown in Fig. 2. The neutron multiplicity probability distributions for thermal-neutron induced fission in ${ }^{235} \mathrm{U}$, for $2 \mathrm{MeV}$ neutrons inducing fission in ${ }^{235} \mathrm{U}$ and ${ }^{235} \mathrm{U}$, and for spontaneous fission in ${ }^{238} \mathrm{U}$ and ${ }^{252} \mathrm{Cf}$ are presented in Fig. 3.[24] Significant differences exist between the spontaneous fission of ${ }^{238} \mathrm{U}$, neutron-induced fission in ${ }^{235} \mathrm{U}$, and spontaneous fission of ${ }^{252} \mathrm{Cf}$.

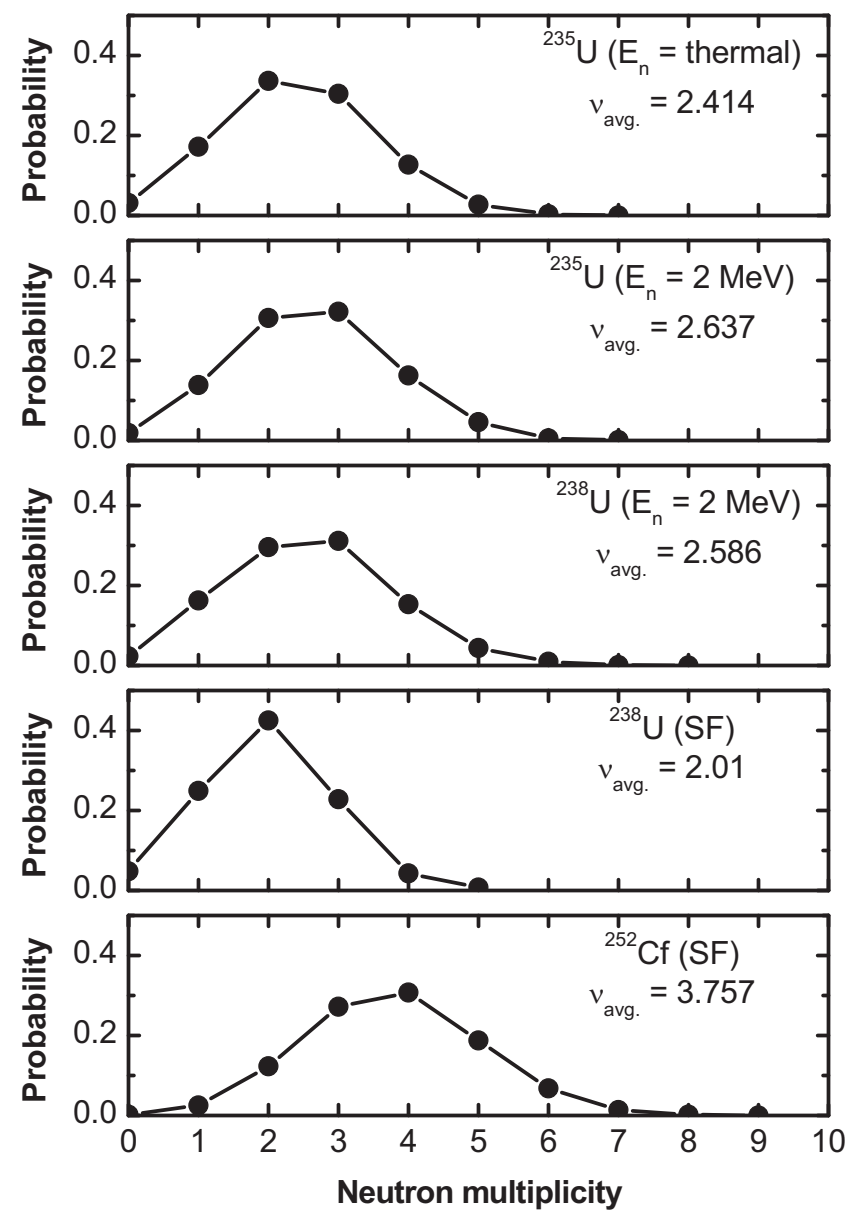

Fig. 3 Induced-fission (neutron energy, $\mathrm{E}_{\mathrm{n}}$, thermal or $2 \mathrm{MeV}$ ) and spontaneous-fission (SF) multiplicity distributions for ${ }^{235} \mathrm{U},{ }^{238} \mathrm{U}$, and ${ }^{252} \mathrm{Cf} .[24]$

\section{MARVEL MODELING AND SIMULATION}

The Monte Carlo n-Particle computer code (MCNP 5), with $\mathrm{k}$-code, was used to assess the bare, unreflected effective multiplication factor, $k_{e f f}$, for several possible configurations of the three MARVEL core components.[25] As-built dimensional measurements were used for the core components, in the model and correct isotopic composition values were used for each section. The top part of the core contains a small penetration, to allow insertion of small diagnostic instruments (e.g., a micro fission chamber or thermocouple). The middle and lower sections of the core contain a recessed channel designed to allow these components to be mounted into a positioning assembly. The 
hole passing along the diameter of the middle section is not centered axially but is closer to the side with the recessed channel. Eight geometric arrangements were analyzed, as depicted in Fig. 4. For each case, the calculated $k_{\text {eff }}$ values, and the leakage multiplication values (determined using (3)), are presented in Table 2 .
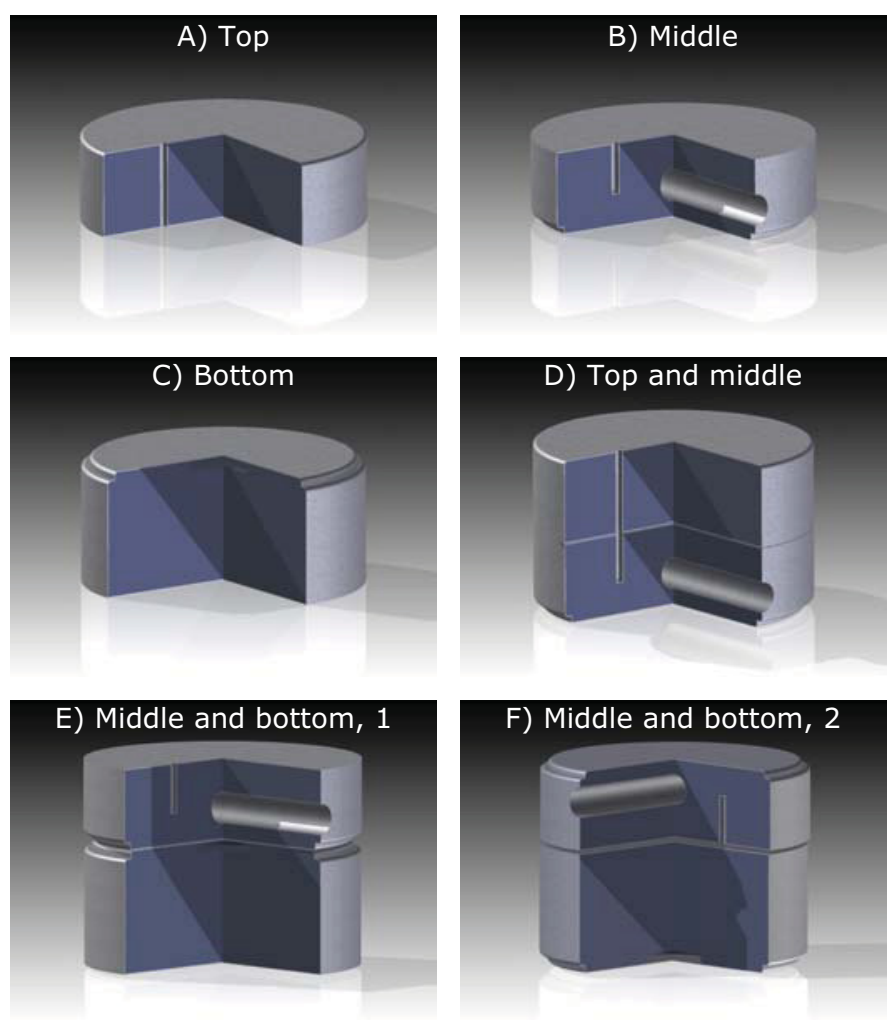

\section{G) Top and bottom}
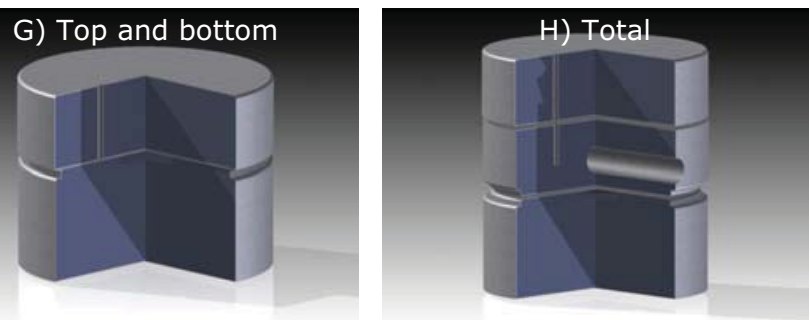

Fig. 4 Eight geometric arrangements of the MARVEL core components.

TABLE 2 Simulated $k_{e f f}$ VALUES FOR EIGHT MARVEL CORE COMPONENT CONFIGURATIONS

\begin{tabular}{lll}
\hline \multicolumn{1}{c}{ Configuration } & \multicolumn{1}{c}{$\boldsymbol{k}_{\text {eff }}$} & $\boldsymbol{M}_{\boldsymbol{L}}$ \\
\hline A) Top & $0.4362 \pm 0.0003$ & 1.774 \\
\hline B) Middle & $0.4097 \pm 0.0003$ & 1.694 \\
\hline C) Bottom & $0.5398 \pm 0.0004$ & 2.173 \\
\hline D) Top and middle & $0.5990 \pm 0.0004$ & 2.494 \\
\hline E) Middle and bottom, 1 & $0.6509 \pm 0.0004$ & 2.865 \\
\hline F) Middle and bottom, 2 & $0.6579 \pm 0.0004$ & 2.923 \\
\hline G) Top and bottom & $0.6700 \pm 0.0004$ & 3.030 \\
\hline H) Total & $0.7248 \pm 0.0005$ & 3.634 \\
\hline$M_{L}$ values determined using equation $(3)$.
\end{tabular}

Additional simulations were performed to determine the effective multiplication factor for two-different configurations when surrounded by reflectors (which in some cases also moderate neutrons) of polyethylene, graphite, stainless steel, and tungsten. The plot of $k_{\text {eff }}$ versus reflector thickness for the top MARVEL core competent is shown in Fig. 5; a similar plot for the top and bottom (layout G of Fig. 4), is shown in Fig. 6.

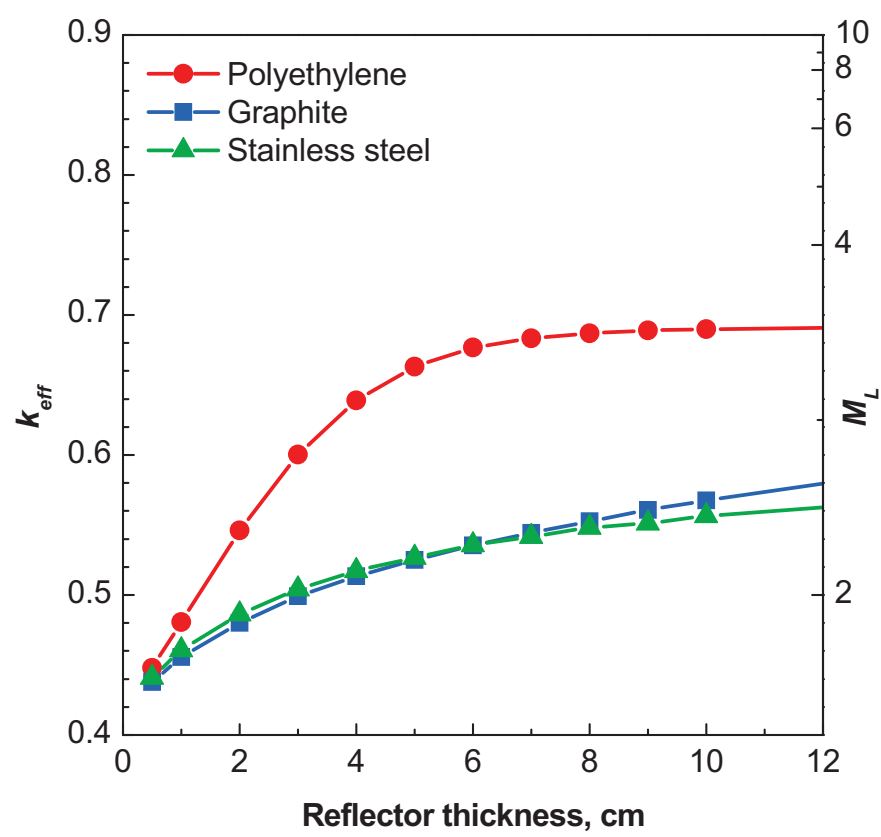

Fig. 5 The relationship between $k_{\text {eff }}, M_{L}$, and reflector thickness for the top MARVEL core component surrounded by polyethylene, graphite, or stainless steel.

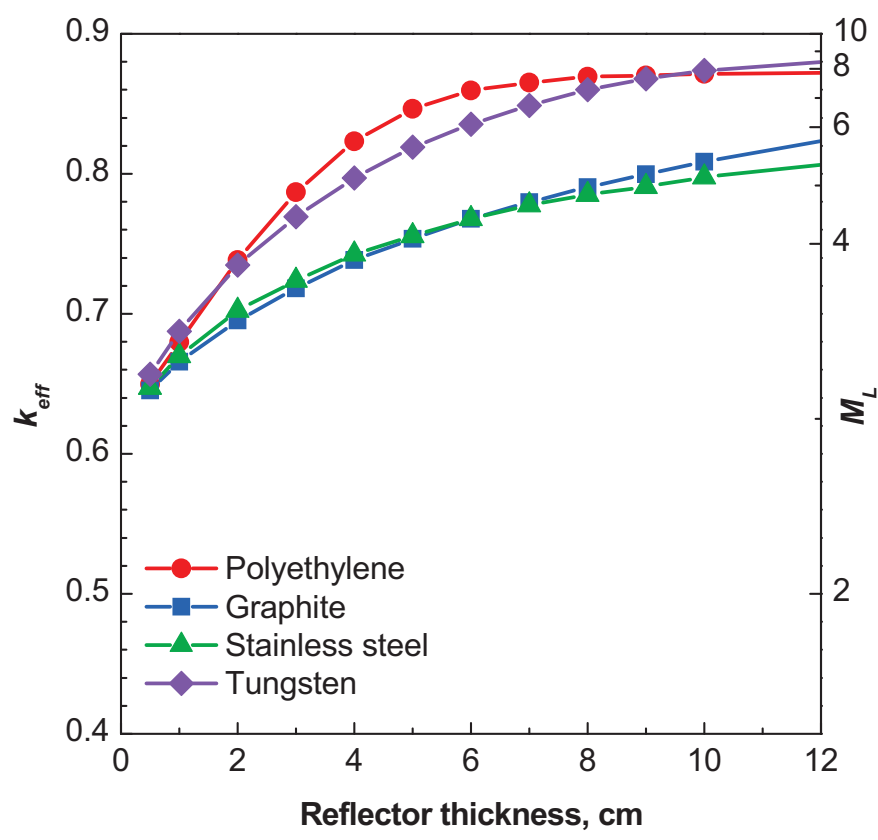

Fig. 6 The relationship between $k_{\text {eff, }}, M_{L}$, and reflector thickness for the top and bottom MARVEL core components surrounded by polyethylene, graphite, stainless steel, or tungsten. 


\section{DEMONSTRATION EXPERIMENT}

In September, 2012, the first set of hands-on subcritical experiments was performed using the MARVEL components. Custom-fitting reflector/moderator assemblies are typically used for these types of tests (see for example, reference 1.) Unfortunately, for this first set of tests with the MARVEL components, custom-fit reflectors/moderators were not yet available. Instead, standard 2 -in. $(5.1-\mathrm{cm}) \times 4$-in. $(10.2-\mathrm{cm}) \times$ 8 -in. $(20.3-\mathrm{cm})$ polyethylene bricks were used to surround the assembly, one brick at a time. The experiment used the top and bottom parts of the core, as shown in layout G of Fig. 4.

The experiment started by placing the stacked core components on a steel support plate under which was an array of cadmium-wrapped, polyethylene-moderated ${ }^{3} \mathrm{He}$ tubes. This served as the leakage neutron detector for the experiment. An AmLi ( $\alpha, n)$ neutron source, packaged inside a steel crimp-lid can, was placed on top of the core components. Neither the core components, the AmLi source, nor the detectors were moved during the experiments. A recoding was made of the neutron counts in the detector array, all counts were taken for $50 \mathrm{~s}$ and had a statistical precision of $<1 \%$. After this, one by one, polyethylene bricks were placed around the assembly and neutron count readings were taken. The loading pattern is shown in Fig. 7 together with a photograph of the assembly taken after placement of the eighth brick. Fourteen bricks were emplaced singly, after this eight more bricks were placed over the top of the assembly and polyethylene bricks, covering the top with 4 inches $(10.2$ $\mathrm{cm})$ of polyethylene.
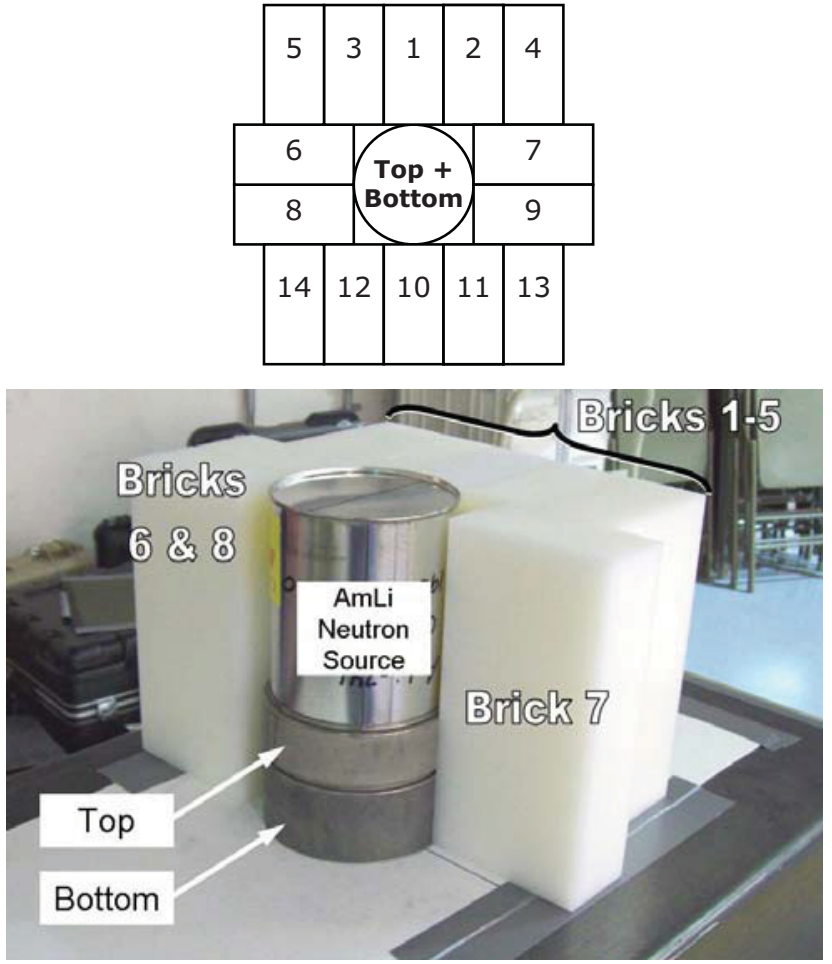

Fig. 7 The top part of this figure shows the schematic loading pattern used to place polyethylene bricks around the top and bottom MARVEL core components. The lower part of this figure is a photograph showing the assembly after brick number 8 was put in place. Also, the location of the AmLi neutron source is visible.
The results from this experiment are shown in Fig. 8. The first five bricks have a small but noticeable effect, slowly increasing the multiplication level of the assembly. Addition of bricks six through eight have a much large impact, as they begin to close-in the core pieces. Further increases are observed as the last side of the assembly is enclosed. Covering the top of the assembly was found to increase the multiplication by approximately $29 \%$. With the sides and top of the assembly surrounded with polyethylene, the observed multiplication factor for this experiment, derived using the measured multiplication value for 22 polyethylene bricks, was 0.67. As expected, this is less than the simulated value of 0.87 shown in Fig. 6 for the ideal case completely surrounding the entire assembly with $10 \mathrm{~cm}$ of polyethylene. The primary cause for this difference is that a non-trivial fraction of the source neutrons are measured in the detectors directly without interacting in the HEU, thus artificially raising the denominator in the equation for $M$. Performing the experiment using more polyethylene underneath the assembly, placing the neutron source inside the top-section experimental hole, and moving the neutron detectors closer to the assembly would all serve to increase the observed multiplication level and work to improve the fidelity between the idealized simulations and the experiments.

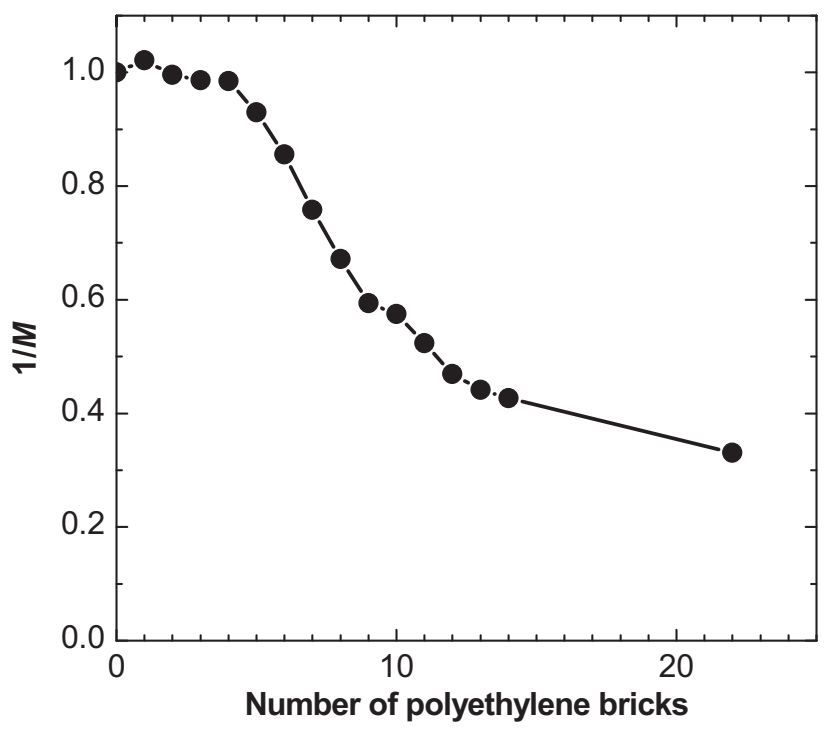

Fig. 8 1/M plot for stacking polyethylene bricks around the assembly of the top and bottom MARVEL components.

\section{SUMMARY}

Activities are underway at Idaho National Laboratory to return the AFSR core to operational use as a subcritical multiplying assembly to support research, validation, evaluation, and learning activities - MARVEL. In support of this goal a series of initial simulations has been performed to assess the bare, unreflected effective multiplication factor, $k_{\text {eff, }}$, for eight different geometric arrangements of the core's three components: top; middle, and bottom. The bare $k_{\text {eff }}$ values range from 0.4362 for the top section of the core to 0.7248 for all three parts of the core. An inaugural experimental campaign has been performed, using the top and bottom sections of the core with polyethylene shield bricks, to 
demonstrate the capability of using the MARVEL assembly for performing a traditional 1/M 'approach-to-critical' experiment. Future work underway at INL to improve the usefulness of the MARVEL components for performing research, validation, evaluation and learning exercises in support of multiplication-related studies includes: acquisition of a small ${ }^{252} \mathrm{Cf}$ spontaneous-fission neutron source suitable for insertion inside the middle section of the core; acquisition of a set of modular, cylindrical reflectors made of polyethylene and tungsten, to allow the execution of more detailed and more reproducible 1/M-type experiments; the acquisition of a smaller neutron detector capable of being placed directly underneath the core, and developing higherfidelity models of the experimental apparatus, including the neutron source, the detector, and the reflectors.

\section{ACKNOWLEDGements}

We would like to acknowledge the dedicated work of the INL staff at the Materials and Fuels Complex ZPPR facility, and thank them for their assistance in working to return the AFSR core to service. We would also like to thank the other INL staff who have participated in this effort, in particular Todd Taylor of INL's Criticality Safety department.

\section{REFERENCES}

[1] Percher, C., Huang, S., and Heinrichs, D., "Hands-on Nuclear Criticality Safety Training at Lawrence Livermore National Laboratory," Report LLNL-PRES-46149, Lawrence Livermore National Laboratory, Livermore, Calif. (2010).

[2] Chichester, D. L., Seabury, E. H., Turnage, J. A., Brush, B. A., and Perry, E. F., "Capabilities of the INL ZPPR to Support Active Interrogation Research with SNM," AIP Conf. Proc. 1099 (2009) 647651.

[3] McConchie, S., et al., "Pulsed D-D Neutron Generator Measurements of HEU Oxide Fuel Pins," Amer. Inst. Phys. Conf. Proc. 1099 (2009) 643646.

[4] Dolan, J. L., et al., "Measurement and Characterization of Nuclear Material at Idaho National Laboratory," J. Nucl. Mat. Manag. 38 (2009) 40.

[5] McConchie, S., Hausladen, P., and Mihalczo, J., "Reflected Neutron Effects in Multiplicity Measurements of Bare HEU Assemblies," Proc. Ann. Meet. Inst. Nucl. Mat. Manag., Baltimore, Md., July 11-16 (2010).

[6] Jones, J. L., et al., "Enhanced Photofission-Based, Coincidence/ Multiplicity Inspection Measurements," Report INL/CON-10-17874, Idaho National Laboratory, Idaho Falls, Id. (2010).

[7] Enqvist, A., et al., "A Combined Neutron and Gamma-Ray Multiplicity Counter Based on Liquid Scintillation Detectors," Nucl. Inst. Meth. Phys. Res. A. 652 (2011) 48-51.

[8] Dolan, J. L., et al., "Active-Interrogation Measurements of InducedFission Neutrons from Low-Enriched Uranium," Proc. Ann. Meet. Inst. Nucl. Mat. Manag., Orlando, Fla., July 15-19 (2012).

[9] Neibert, R. et al., "Passive and Active Radiation Measurements Capability at the INL Zero Power Physics Reactor (ZPPR) Facility," Report INL/EXT-11-20876, Idaho National Laboratory, Idaho Falls, Id. (2011).

[10] Chichester, D. L., et al., "Parametric Evaluation of Active Neutron Interrogation for the Detection of Shielded Highly-Enriched Uranium in the Field," Conf. Rec., IEEE Nucl. Sci. Symp., Valencia, Spain, October 23 - 29 (2011) 964-971.

[11] Kaplan, A. C., et al., "Validation of the MCNPX-PoliMi Code to Design a Fast-Neutron Multiplicity Counter," Proc. Ann. Meet. Inst. Nucl. Mat. Manag. Orlando, Fla., July 15-19 (2012).

[12] Fullwood, R., "Lecture Notes for Criticality Safety," Report BNL47594, Brookhaven National Laboratory, Upton, N. Y. (1992).

[13] "Criticality Safety Basics for INL FMHs and CSOs," Report INL/EXT06-01183 Rev. 1, Idaho National Laboratory, Idaho Falls, Idaho (2006).
[14] "Guidance for Nuclear Criticality Safety Engineer Training and Qualification," DOE Standard DOE-STD-1135-99, U.S. Department of Energy, Washington, D. C. (1999).

[15] Wagemans, C., The Nuclear Fission Process, CRC Press, Baton Rouge, La. (1991) 514.

[16] Serber, R., "The Definition of "Neutron Multiplication,"' Report LA335, Los Alamos Scientific Laboratory, Los Alamos, N.M. (1945).

[17] Carlson, B., "A Note on the Calculation of Neutron Multiplication," Report LA-1273, Los Alamos Scientific Laboratory, Los Alamos, N.M. (1951).

[18] Profio, A. E., Experimental Reactor Physics, John Wiley and Sons, New York, N.Y. (1976) 603.

[19] Brewer, R. W., "The Relationship Between Neutron Multiplication and keff," Report LA-UR-95-2127, Los Alamos National Laboratory, Los Alamos, N.M. (1995).

[20] "Nuclear Physics and Reactor Theory, Vol. 2, DOE Fundamentals Handbook," Report DOE-HDBK-1019/2-93, U.S. Department of Energy, Washington, D. C. (1993).

[21] Keepin, G. R., Physics of Nuclear Kinetics, Addison-Wesley Publishing Company, Reading, Mass. (1965).

[22] Maslov, V. M., "Prompt-Fission-Neutrons Spectra of ${ }^{238} \mathrm{U}$," Phys. Atomic Nuclei 71 (2008) 9-26.

[23] Ensslin, N., "The Origin of Neutron Radiation," in "Passive Nondestructive Assay of Nuclear Materials," Report NUREG/CR-5550, U.S. Nuclear Regulatory Commission, Washington, D.C. (1991).

[24] Verbeke, J. M., Hagmann, C., and Wright, D., "Simulation of Neutron and Gamma Ray Emission from Fission and Photofission," Report UCRL-AR-228518, Lawrence Livermore National Laboratory, Livermore, Calif. (2010).

[25] "MCNP-A General Monte Carlo N-Particle Transport Code, Version 5," Report LA-UR-03-1987, Los Alamos National Laboratory, Los Alamos, N.M. (2003). 